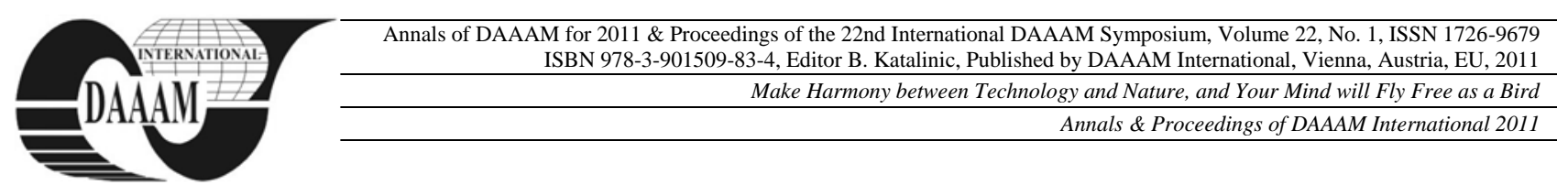

\title{
MATLAB TOOLBOXES FOR FRACTIONAL ORDER CONTROL: AN OVERVIEW
}

\author{
MATUSU, R[adek]
}

\begin{abstract}
The main aim of this contribution is to present several existing toolboxes for Matlab and Simulink environment which are dedicated to fractional order control and which should assist a user with convenient solution of this type of analysis and synthesis problems. The fundamentals of fractional order calculus and brief outline of fractional order controllers are followed by overview of four selected toolboxes including the references to sources for obtaining the described packages
\end{abstract}

Key words: fractional order control, matlab, simulink, toolboxes

\section{INTRODUCTION}

The Fractional Order Calculus (FOC) represents the mathematical branch dealing with differentiation and integration under an arbitrary order of the operation. It means that the order can be any real or even complex number, not only the integer one (Oldham \& Spanier, 1974; Miller \& Ross, 1993; Podlubný, 1999a).

In spite of the fact that FOC is more than 300-year-old issue (Chen et al., 2009; Petráš, 2009), as follows from the correspondence between Leibniz and L'Hospital in 1695, its great consequences in contemporary theoretical research and real world applications have been widely discussed relatively recently. The FOC has already came in useful in many attractive engineering areas such as bioengineering, viscoelasticity, electronics, robotics, control theory and signal processing (Gutiérrez et al., 2010).

This contribution is focused mainly on brief presentation of four existing Matlab and Simulink toolboxes for fractional order control which are intended to conveniently assist a user with such kind of analysis and synthesis problems (Matušů, 2011a; Matušů, 2011b).

\section{FUNDAMENTALS OF FRACTIONAL ORDER CALCULUS}

The basic tool which is used to express generalization of differentiation and integration to an arbitrary order (rational, irrational or even complex) is the continuous differintegral operator (Oldham \& Spanier, 1974; Miller \& Ross, 1993; Chen et al., 2009; Gutiérrez et al., 2010):

$$
{ }_{a} D_{t}^{\alpha}= \begin{cases}\frac{d^{\alpha}}{d t^{\alpha}} & \operatorname{Re} \alpha>0 \\ 1 & \operatorname{Re} \alpha=0 \\ \int_{a}^{t}(d \tau)^{-\alpha} & \operatorname{Re} \alpha<0\end{cases}
$$

where $\alpha$ is the order of the differintegration and $a$ is a constant related to initial conditions. The most frequent scenario supposes $\alpha \in \square$.
There are a number of various definitions of the differintegral in scientific literature. Probably the most known and used Riemann-Liouville version has the form (Chen et al., 2009):

$$
{ }_{a} D_{t}^{\alpha} f(t)=\frac{1}{\Gamma(n-\alpha)} \frac{d^{n}}{d t^{n}} \int_{a}^{t} \frac{f(\tau)}{(t-\tau)^{\alpha-n+1}} d \tau
$$

under assumption $(n-1<\alpha<n)$. The term $\Gamma(\cdot)$ represents socalled Gamma function. The other two commonly utilized definitions bear the names of Grünwald-Letnikov and Caputo (Podlubný, 1999a; Podlubný, 1999b; Chen et al., 2009; Petráš, 2009).

Many information on issues connected with control applications of FOC, such as description of fractional order systems and their stability, can be found e.g. in (Podlubný, 1999b; Chen et al., 2009; Petráš, 2009).

\section{FRACTIONAL ORDER CONTROLLERS}

Contemporary works usually distinguish among the four main approaches to fractional order control (Xue \& Chen, 2002; Chen et al., 2009; Gutiérrez et al., 2010). These methods are:

- Tilted Proportional and Integral (TID) Controllers (Lurie, 1994): They have the same structure as classical PID controllers, but the proportional gain is replaced with a function $s^{-\alpha}$ where $\alpha \in \square$.

- CRONE (Oustaloup et al., 1998; Oustaloup et al., 2000; Melchior et al., 2001; CRONE Toolbox - Official Website, 2011): The popular frequency-domain based control approach inspired by the fractal robustness. The abbreviation CRONE stands for French "Commande Robuste d'Ordre Non Entier" (non-integer order robust control). It has been already developed three generations of the CRONE methodology with many real control applications.

- Fractional Order PID Controllers (Podlubný, 1999b): The elegant and efficient fractional order modification of conventional PID controllers which is known as $P I^{\lambda} D^{\mu}$ controllers and which offers much greater variety of controller parameters.

- Fractional Lead-Lag Controllers (Raynaud \& Zergaïnoh, 2000): The extension of the classical leadlag controllers to their fractional version.

\section{OVERVIEW OF MATLAB TOOLBOXES}

The computations and simulations connected with fractional order control issues can be conveniently performed using one of existing Matlab and Simulink toolboxes. Some of them are going to be briefly introduced in this section (Matušů, 2011b). 


\subsection{CRONE Toolbox}

The CRONE Toolbox for Matlab and Simulink, dedicated to fractional order calculus, is deeply elaborated product which contains the implementations of the original theoretical and mathematical concepts developed by the CRONE research group (Oustaloup et al., 1998; Oustaloup et al., 2000; Melchior et al., 2001). Nowadays, there are two versions of the toolbox available - a classical and an object oriented one. Both of them can be downloaded (after registration) from the Internet (CRONE Toolbox - Official Website, 2011).

The classical version is embellished with a Guided User Interface and has three main modules (CRONE Toolbox Official Website, 2011):

- Mathematical module - implementation of fractional calculus algorithm

- System identification module - identification of fractional order models in frequency and time domain

- CRONE control module - implementation of fractional order robust control design

The object oriented version contains various scripts which allow overloading some basic mathematical operators and standard Matlab routines for the fractional order cases and supposes user who is familiar with the basics of work with Matlab (CRONE Toolbox - Official Website, 2011).

\subsection{Ninteger Toolbox}

The principal goal of the "Ninteger" toolbox for Matlab (Valério \& da Costa, 2004; Valério, 2011) is to assist with the design of fractional order controllers and with their performance assessment. The toolbox was developed by Duarte Pedro Mata de Oliveira Valério and can be downloaded from the webpage (Valério, 2011). It employs over thirty formulas for approximating the non-integer order derivatives. Moreover, the toolbox implements non-integer PID controllers and second and third-generation CRONE controllers. On the top of that, it contains functions for computing norms, model identification and frequency diagrams. Finally, the toolbox is enriched with a Graphical User Interface and has a Simulink library.

\subsection{FOTF Toolbox}

The Fractional Order Transfer Function (FOTF) Matlab Toolbox was presented in the tutorial paper (Chen et al., 2009). The toolbox consists of the functions located in the @ fotf folder (in order to define the FOTF class). Those functions cover basic operations with FOTF objects, stability testing, simulations of time responses, various frequency characteristics plotting, etc. The interested reader can find the full codes of the mentioned routines as well as an array of illustrative examples of their application in (Chen et al., 2009).

\subsection{Matlab Scripts by Ivo Petráš}

Several useful scripts related to fractional order control can be found also at the webpage (Petráš, 2011). They cover for example frequency characteristics, step and impulse responses, or digital fractional order differentiators/integrators.

\section{CONCLUSION}

The contribution was mainly intended to provide an overview of toolboxes for fractional order control under Matlab and Simulink environment. More specifically, the basic purposes and capabilities of the CRONE Toolbox, Ninteger Toolbox, FOTF Toolbox, and codes by Ivo Petráš were briefly presented including the ways how to get the programs and source codes.

\section{ACKNOWLEDGEMENTS}

The work was supported by the Ministry of Education, Youth and Sports of the Czech Republic under the Research
Plan No. MSM 7088352102 and by the European Regional Development Fund under the project CEBIA-Tech No. CZ.1.05/2.1.00/03.0089. This assistance is very gratefully acknowledged.

\section{REFERENCES}

Chen, Y.; Petráš, I. \& Xue, D. (2009). Fractional Order Control - A Tutorial, In: Proceedings of the 2009 American Control Conference, St. Louis, MO, USA

CRONE Toolbox - Official Website. (2011). [Online]. [Accessed July 7, 2011]. Available from URL: http://www.ims-bordeaux.fr/CRONE/toolbox/

Gutiérrez, R. E.; Rosário, J. M. \& Machado, J. T. (2010). Fractional Order Calculus: Basic Concepts and Engineering Applications. Mathematical Problems in Engineering, Vol. 2010, $19 \mathrm{p}$

Lurie, B. J. (1994). Three-parameter tunable tilt-integralderivative (TID) controller. US Patent US5371670

Matušů, R. (2011a). Fractional Order Calculus in Control Theory, In: Proceedings of the 13th WSEAS International Conference on Automatic Control, Modelling \& Simulation, Lanzarote, Spain, pp. 314-317

Matušů, R. (2011b). Application of fractional order calculus to control theory. International Journal of Mathematical Models and Methods in Applied Sciences, Submitted manuscript

Melchior, P.; Orsoni, B.; Lavialle, O. \& Oustaloup, A. (2001). The CRONE Toolbox for Matlab: Fractional Path Planning Design in Robotics, In: Proceedings of the 10th IEEE International Workshop on Robot and Human Interactive Communication, Bordeaux and Paris, France

Miller, K. S. \& Ross, B. (1993). An Introduction to the Fractional Calculus and Fractional Differential Equations, John Wiley and Sons, New York, USA

Oldham, K. B. \& Spanier, J. (1974). Fractional Calculus: Theory and Applications of Differentiation and Integration to Arbitrary Order, Academic Press, New York - London

Oustaloup, A.; Melchior, P.; Lanusse, P.; Cois, O. \& Dancla, F. (2000). The CRONE toolbox for Matlab, In: Proceedings of the 2000 IEEE International Symposium on ComputerAided Control System Design, Anchorage, Alaska, USA

Oustaloup, A.; Sabatier, J. \& Moreau, X. (1998). From fractal robustness to the CRONE approach. ESAIM Proceedings, Vol. 5, pp. 177-192

Petráš, I. (2009). Stability of fractional-order systems with rational orders: A survey. Fractional Calculus \& Applied Analysis, Vol. 12, No. 3, pp. 269-298

Petráš, I. (2011). Software pages of Dr. Ivo Petráš. [Online]. [Accessed July 7, 2011]. Available from URL: http://people.tuke.sk/ivo.petras/SW.html

Podlubný, I. (1999a). Fractional Differential Equations, Academic Press, San Diego, CA, USA

Podlubný, I. (1999b). Fractional-Order Systems and $P I^{\lambda} D^{\mu}$ Controllers. IEEE Transactions on Automatic Control, Vol. 44, No. 1, pp. 208-214

Raynaud, H.-F. \& Zergaïnoh, A. (2000). State-space representation for fractional order controllers. Automatica, Vol. 36, No. 7, pp. 1017-1021

Valério, D. \& da Costa, J. S. (2004). Ninteger: A non-integer control toolbox for Matlab, In: Proceedings of the 1st IFAC Workshop on Fractional Differentiation and its Applications, Bordeaux, France

Valério, D. (2011). Toolbox ninteger for MatLab. [Online]. [Accessed July 7, 2011]. Available from URL: http://web.ist.utl.pt/duarte.valerio/ninteger/ninteger.htm

Xue, D. \& Chen, Y. (2002). A Comparative Introduction of Four Fractional Order Controllers, In: Proceedings of the 4th World Congress on Intelligent Control and Automation, Shanghai, China 